Mathias Hildebrandt - Manfred Brocker (Hrsg.)

Unfriedliche Religionen? 


\title{
Politik und Religion
}

\author{
Herausgegeben von \\ Manfred Brocker (Universität zu KöIn) und Mathias Hildebrandt \\ (Universität Erlangen-Nürnberg)
}

In allen Gesellschaften spielte der Zusammenhang von Politik und Religion eine wichtige, häufig eine zentrale Rolle. Auch die Entwicklung der modernen westlichen Gesellschaften ist ohne die politische Auseinandersetzung mit den traditionellen religiösen Ordnungskonzepten und Wertvorstellungen nicht denkbar. Heute gewinnen im Westen - und weltweit - religiöse Orientierungen und Differenzen erneut einen zunehmenden gesellschaftlichen und politischen Einfluss zurück. Die Buchreihe „Politik und Religion" trägt dieser aktuellen Tendenz Rechnung. Sie stellt für die Sozialwissenschaften in Deutschland, insbesondere aber für die Politikwissenschaft, ein Publikationsforum bereit, um relevante Forschungsergebnisse zum Zusammenhang von Politik und Religion der wissenschaftlichen Öffentlichkeit vorzustellen und weitere Forschungsarbeiten auf diesem Gebiet anzuregen. Sie ist deshalb offen für verschiedene disziplinäre und interdisziplinäre, theoretisch-methodologische und interkulturell-vergleichende Ansätze und fördert Arbeiten, die sich systematisch und umfassend mit politikwissenschaftlich ergiebigen Fragestellungen zum Verhältnis von Politik und Religion befassen. Die wissenschaftliche Auseinandersetzung mit „Politik und Religion” soll damit in ihrer ganzen Breite dokumentiert werden, ohne dass die Herausgeber dabei mit den jeweilig bezogenen Positionen übereinstimmen müssen. 
Mathias Hildebrandt

Manfred Brocker (Hrsg.)

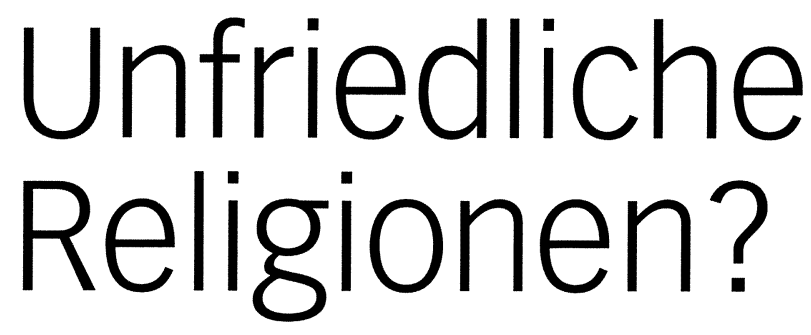

Das politische Gewalt- und

Konfliktpotenzial

von Religionen 


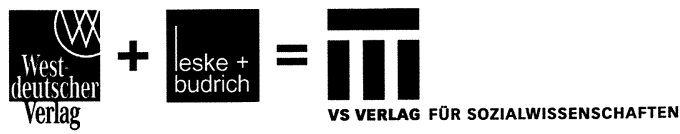

VS Verlag für Sozialwissenschaften

Entstanden mit Beginn des Jahres 2004 aus den beiden Häusern

Leske+Budrich und Westdeutscher Verlag.

Die breite Basis für sozialwissenschaftliches Publizieren

Bibliografische Information Der Deutschen Bibliothek

Die Deutsche Bibliothek verzeichnet diese Publikation in der Deutschen Nationalbibliografie; detaillierte bibliografische Daten sind im Internet über <http://dnb.ddb.de> abrufbar.

\section{Auflage Juli 2005}

Alle Rechte vorbehalten

(C) VS Verlag für Sozialwissenschaften/GWV Fachverlage GmbH, Wiesbaden 2005

Lektorat: Frank Schindler / Nadine Kinne

Der VS Verlag für Sozialwissenschaften ist ein Unternehmen von Springer Science+Business Media. www.vs-verlag.de

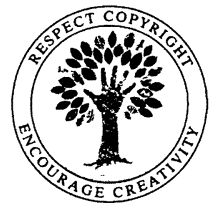

Das Werk einschließlich aller seiner Teile ist urheberrechtlich geschützt. Jede Verwertung außerhalb der engen Grenzen des Urheberrechtsgesetzes ist ohne Zustimmung des Verlags unzulässig und strafbar. Das gilt insbesondere für Vervielfältigungen, übersetzungen, Mikroverfilmungen und die Einspeicherung und Verarbeitung in elektronischen Systemen.

Die Wiedergabe von Gebrauchsnamen, Handelsnamen, Warenbezeichnungen usw. in diesem Werk berechtigt auch ohne besondere Kennzeichnung nicht zu der Annahme, dass solche Namen im Sinne der Warenzeichen- und Markenschutz-Gesetzgebung als frei zu betrachten wären und daher von jedermann benutzt werden dürften.

Umschlaggestaltung: KünkelLopka Medienentwicklung, Heidelberg Gedruckt auf säurefreiem und chlorfrei gebleichtem Papier 


\section{Inhaltsverzeichnis}

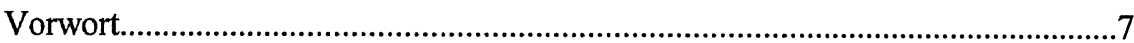

\section{Mathias Hildebrandt}

Einleitung: Unfriedliche Religionen?

Das politische Gewalt- und Konfliktpotenzial von Religionen

\section{Das Gewalt- und Konfliktpotenzial Politischer Theologien}

\section{Dietrich Jung}

„Der Islam gegen den Westen“.

Zur Genealogie eines internationalen Konfliktparadigmas.

Hendrik Hansen

Ein Strukturvergleich von Sayyid Qutbs Islamismus

mit Marxismus und Nationalsozialismus

\section{Manfred Walther}

Strategien der politischen Neutralisierung des Gewaltpotenzials monotheistischer Offenbarungsreligionen.

\section{Dimensionen politisch-religiöser Konflikte}

Claudia Derichs

"Form follows function"?

Popular Islamic Discourse in Malaysia

\section{Mark Arenhövel}

Die Erfindung der Pancasila.

Zur Konstruktion einer staatsreligiösen Einheitsvision in Indonesien

Armin Pfahl-Traughber

Vom Aufbau von Parallelgesellschaften bis zur Durchführung von

Terroranschlägen.

Das Gefahren- und Konfliktpotential des Islamismus in Deutschland 
Helmut Hubel

Wie viel Religion ist in den Konflikten des Vorderen Orient?

Christian Wagner

Der indisch-pakistanische Konflikt als Religionskonflikt?

\section{Ethno-religiöse Bürgerkriege}

Bernhard Moltmann

Die religiöse Dimension des Nordirlandkonfliktes.

Risiken der Konfliktverschärfung und Chancen der Friedensstiftung.

Stephanie van de Loo

Religion als Kriegsgewand?

Zur Rolle von Religion im Krieg in Bosnien-Herzegowina 1991 - 1995.

.225

Jakob Rösel

Buddhismus und Nationalismus:

Feindbilder und Geschichtsbilder des Singhalesischen Nationalismus

Jeff Haynes

Religion in African Civil Wars.

\section{Religion zwischen Gewalt und Versöhnung}

Gordon Mitchell

Religion in Processes of Liberalization, Consolidation and Nation Building. The Case of South Africa. 